Article

\title{
Preparation, Characterization and in Vivo Antimycobacterial Studies of Panchovillin-Chitosan Nanocomposites
}

\author{
Edward Rwegasila ${ }^{1}$, Egid B. Mubofu ${ }^{1}$, Stephen S. Nyandoro ${ }^{1}$, Paul Erasto ${ }^{2}$ \\ and Joan J. E. Munissi ${ }^{1, *}$ \\ 1 Chemistry Department, College of Natural and Applied Sciences, University of Dar es Salaam, \\ P.O. Box 35061, 14115 Dar es Salaam, Tanzania; edrwega@yahoo.com (E.R.); \\ ebmubofu@udsm.ac.tz (E.B.M.); nyandoro@udsm.ac.tz (S.S.N.) \\ 2 National Institute for Medical Research (NIMR), P.O. Box 9653, 14115 Dar es Salaam, Tanzania; \\ paulkazyoba@yahoo.co.uk \\ * Correspondence: joan.munissi@udsm.ac.tz; Tel.: +255-222-410-038 \\ Academic Editor: Már Másson \\ Received: 18 July 2016; Accepted: 30 August 2016; Published: 27 September 2016
}

\begin{abstract}
Chitosan (CS, molecular weight $20.2 \mathrm{kDa}$, degree of deacylation (DD) 73.31\%) was successfully obtained by deacetylation of chitin extracted from shrimp (Litopenaeus vannamei) shell wastes. The encapsulation of the bioactive natural product, panchovillin (PANV), isolated from Erythrina schliebenii, on a chitosan-tripolyphosphate (CS/TPP) nano-framework was achieved by ionotropic gelation. Characterization of pure CS, CS/TPP and PANV-CS/TPP nanocomposites was performed by FTIR, SEM and XRD. The molecular weight of chitosan and the thermal stability of the materials were determined by MALDI-TOF-MS and simultaneous thermal analyzer (STA)/DTG, respectively. The respective encapsulation efficiency and loading capacity of the PANV were found to be $70 \%$ and $0.36 \%$. The in vitro release studies showed an initial burst of $42 \%$ of PANV in the first six hours. This was followed by a slow and sustained release up to $72 \mathrm{~h}$. The in vivo antimycobacterial activities of both PANV and PANV-CS/TPP nanocomposite against Mycobacterium indicus pranii (MIP) using Galleria mellonella larvae as an in vivo infection model are reported in this paper.
\end{abstract}

Keywords: panchovillin; chitosan; nanocomposites; antimycobacterial; Galleria mellonella

\section{Introduction}

Nanotechnology is a multidisciplinary field that employs proficiencies and tools from diverse disciplines [1]. The technology has offered tremendous advancement in the field of therapeutics by means of designing various drug delivery systems, thereby increasing the possibilities of controlling infections at the molecular level [2]. The nanoparticle-based systems exhibit significant potential for treatment and prevention of tuberculosis due to their ability to intersect biological barriers and targeting the cellular reservoirs of Mycobacterium tuberculosis (MTB) [2]. Appreciable interest in the search for potential biomedical applications of biomaterials, such as exosomes, liposomes and chitosan, as carriers of therapeutic agents has been reported [1,3]. Over the years, interest in chitosan has dramatically grown due to its novel properties, such as biocompatibility, biodegradability, affordability, stability, low toxicity, as well as its simple and moderate preparation procedures. Moreover, chitosan offers various administration routes, such as oral, nasal and ocular mucosa, making it one of the most significantly attractive materials for drug delivery [4,5]. Chitosan has been investigated as a carrier of bioactive molecules to various target cells, such as cancer cells [6]. However, scanty information is available on the application of chitosan in the delivery of potential anti-TB drugs. The treatment of tuberculosis currently involves the use of first line anti-tubercular drugs, such as rifampicin, isoniazid, 
ethambutol and pyrazinamide [7]. Longer treatment periods (approximately six to twelve months) have always posed a threat of attrition to treatment, leading to the development of drug-resistant TB strains. Thus, the application of nanotechnology to improve drug delivery and bioavailability is likely to reduce the treatment time and improve compliance and outcome $[1,8]$. Natural products possessing inhibitory activity against MTB have been reported from higher and lower forms of plants, microorganisms and marine organisms [9]. In most cases, natural products are rendered inactive in vivo due to low solubility, poor stability, low bioavailability and lack of target specificity, leading to inaccessibility at their most effective levels at the target site. Thus, formulating delivery systems that optimize the effectiveness of the compounds while minimizing their side effects is a crucial means of addressing the challenges associated with the treatment of MTB.

Polyphenols are economically important compounds that have found various applications, such as natural additives, food complements or have been incorporated into cosmetic or pharmaceutical formulations. However, the application of polyphenols is limited [10]; due to poor bioavailability arising from insufficient gastric residence time, low permeability and/or low solubility. These factors limit the activity and the potential health benefits of most polyphenols. Their tendency to oxidize easily in their free form leads to a considerable loss in activity. Therefore, the optimal exploitation and application of these compounds require that the drawbacks are circumvented in order to ensure that they reach a physiological target at desirable concentrations. This study therefore aimed at investigating the potential of improving the efficacy of panchovillin by encapsulation onto chitosan. Panchovillin (PANV; Figure 1) is a naturally-occurring polyphenol that has been reported from a variety of plant species, including Erythrina schliebenii, a rare and critically endangered plant species endemic to Tanzania [11]. The compound has been found to possess in vitro activities against Mycobacterium tuberculosis (H37Rv) and cytotoxicity against the aggressive human breast cancer cells (MDA-MB-231) [12]. Panchovillin was therefore selected as a representative polyphenol, while Mycobacterium indicus pranii (MIP) was chosen as a test organism using Galleria mellonella larvae as in vivo infection model to study the antimycobacterial properties of PANV and PANV-chitosan (CS)/tripolyphosphate (TPP) nanocomposites.

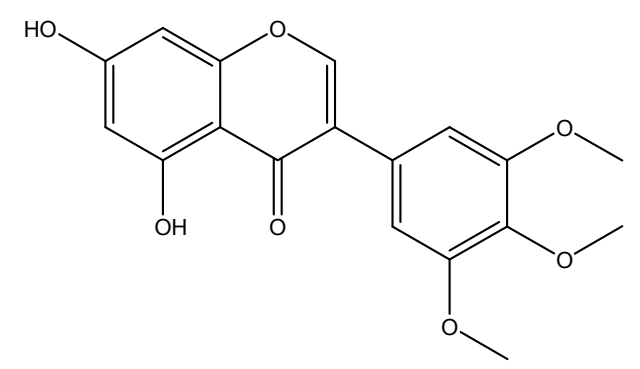

Figure 1. Chemical structure of panchovillin (PANV).

\section{Results and Discussion}

\subsection{IR Analysis}

The IR spectra of chitin and chitosan are shown in Figure 2. The IR spectrum of chitin (Figure 2) was characterized by three important amide bands at 1624, 1555 and $1308 \mathrm{~cm}^{-1}$, which correspond to the stretching vibration of $\mathrm{C}=\mathrm{O}$, the bending vibration of the amide II band and $\mathrm{C}-\mathrm{N}$ stretching vibration, respectively [13]. Other absorption bands observed at 3261, 2878 and $1153 \mathrm{~cm}^{-1}$ were attributed to $\mathrm{O}-\mathrm{H}, \mathrm{C}-\mathrm{H}$ and $\mathrm{C}-\mathrm{O}$ stretching vibrations, respectively, thereby confirming that the purified material was indeed chitin [14]. The infra-red spectrum of chitosan (Figure 2) exhibited a characteristic band at $3361 \mathrm{~cm}^{-1}$ attributed to the stretching vibration of the inter- and intra-molecular hydrogen bonds from the $-\mathrm{NH}_{2}$ and $-\mathrm{OH}$ groups, being similar to the previously-reported results [15]. The weak absorption band at $2925 \mathrm{~cm}^{-1}$ was assigned to $s p^{3} \mathrm{C}-\mathrm{H}$ stretching vibrations. The intense 
peak around $1555 \mathrm{~cm}^{-1}$ corresponds to the bending vibration of $\mathrm{NH}_{2}$, a significant feature for chitosan. The higher intensity of this peak in chitosan compared to that observed in chitin and subsequent shortening of the peak intensity due to $\mathrm{C}=\mathrm{O}$ stretch at $1651 \mathrm{~cm}^{-1}$ (Figure 2) indicates that deacetylation was successful $[16,17]$. The peak for the asymmetric stretch of $\mathrm{C}-\mathrm{O}-\mathrm{C}$ was observed at $1151 \mathrm{~cm}^{-1}[15,18,19]$. The peaks at 1651 and $1372 \mathrm{~cm}^{-1}$ were attributed to $\mathrm{C}=\mathrm{O}$ and $\mathrm{C}-\mathrm{N}$ stretching vibration as amide I and amide III of chitosan, respectively [15].

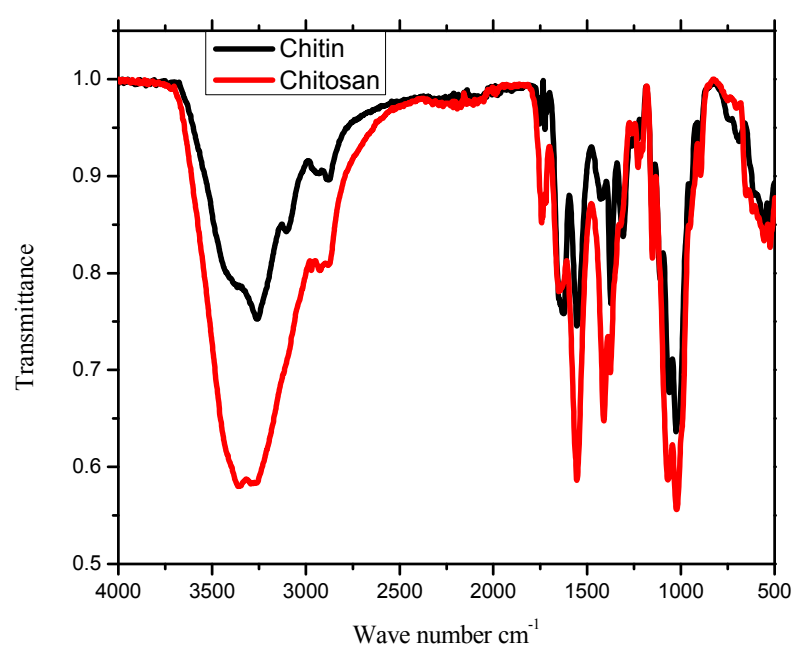

Figure 2. IR spectra of chitin and chitosan.

Formation of CS/TPP nanomaterial was confirmed by comparing the IR spectra of pure CS and CS/TPP nanomaterial (Figure 3). The IR spectra revealed the peak at $3361 \mathrm{~cm}^{-1}$ in pure CS that had shifted to $3204 \mathrm{~cm}^{-1}$ in CS/TPP nanomaterial (Figure 3) and broadened with decreased relative intensity at a ratio of 3:1 $\left(\mathrm{A}_{3361} / \mathrm{A}_{3204}\right)$, manifesting an enhancement of hydrogen bonding [19]. The peak for the N-H bending vibration of amide II at $1555 \mathrm{~cm}^{-1}$ in CS had shifted to $1535 \mathrm{~cm}^{-1}$ in CS/TPP nanomaterial with relative reduced intensity at approximately a 5:1 ratio $\left(\mathrm{A}_{1555} / \mathrm{A}_{1535}\right)$, while the amide I $C=O$ stretch observed at $1651 \mathrm{~cm}^{-1}$ in CS shifted to $1625 \mathrm{~cm}^{-1}$ in CS/TPP (Figure 3). A new peak observed at $1214 \mathrm{~cm}^{-1}$ was attributed to a $\mathrm{P}=\mathrm{O}$ stretching vibration, confirming a cross-linkage between CS and TPP during fabrication of the nanomaterials [19,20].

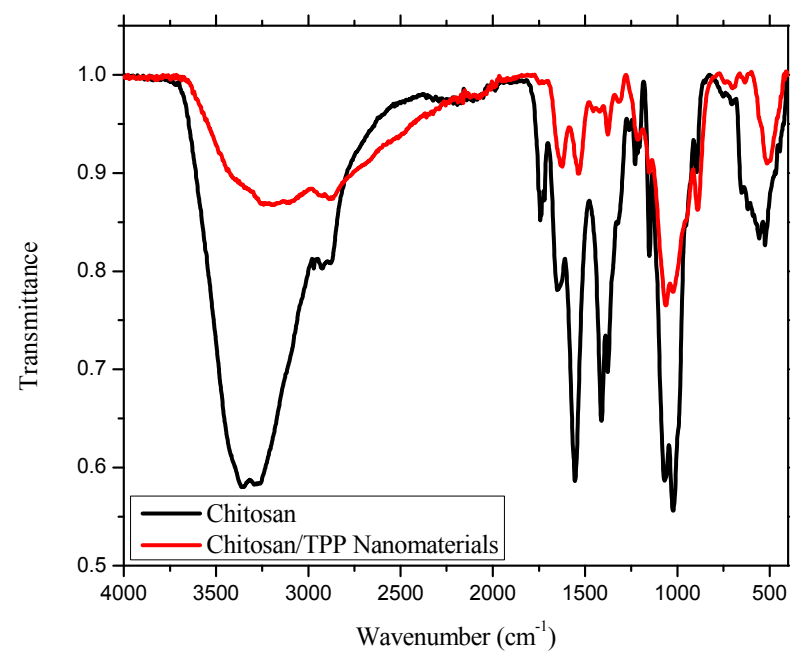

Figure 3. IR spectra of chitosan (CS) and CS/tripolyphosphate (TPP) nanomaterials. 
The IR spectrum of the PANV-CS/TPP nanocomposites showed a shift of absorption peaks when compared to the free chitosan nanomaterials (Figure 4). The absorption peak observed at $3208 \mathrm{~cm}^{-1}$ corresponds to $\mathrm{OH}$ and $\mathrm{N}-\mathrm{H}$, while other peaks at 1621, 1523, 1215 and $1155 \mathrm{~cm}^{-1}$ were assigned to the amide $\mathrm{I}(\mathrm{C}=\mathrm{O})$ band, the amide II band, the $\mathrm{P}=\mathrm{O}$ stretch and the asymmetric stretch of $\mathrm{C}-\mathrm{O}$, respectively (Figure 4). The new peak observed at $1733 \mathrm{~cm}^{-1}$ is due to the ketonic $\mathrm{C}=\mathrm{O}$ stretch of PANV, confirming the successful encapsulation of the compound on the CS/TPP nano-framework. The encapsulation of PANV within the CS/TPP framework is probably enhanced by the hydrogen bonding between the methoxy and hydroxyl groups present in PANV and the hydroxyl groups on the polymer (Figure 5).

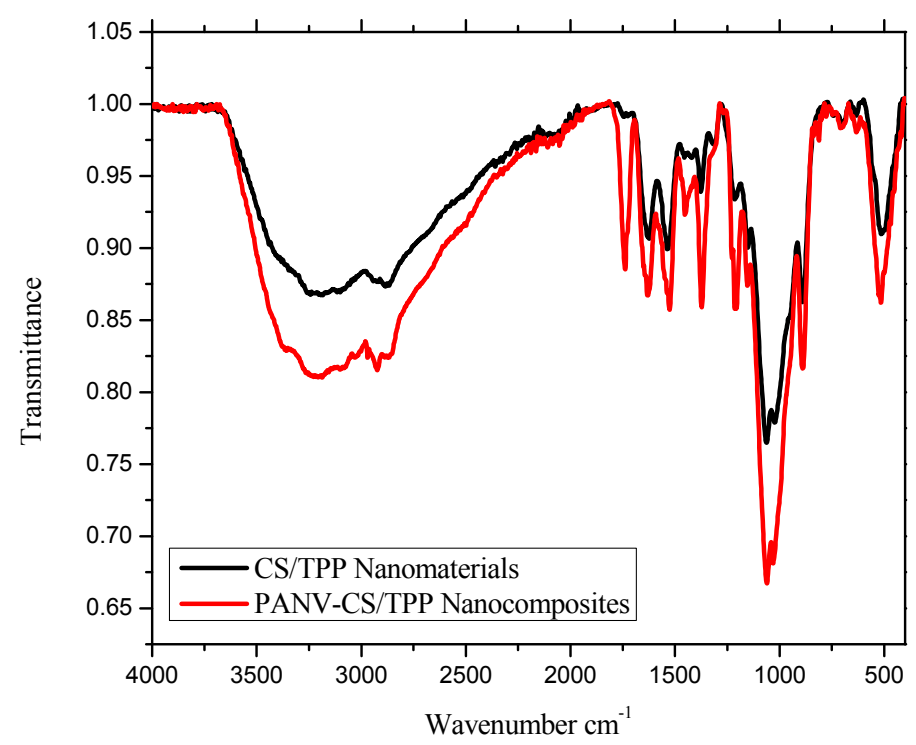

Figure 4. FTIR spectra of free CS/TPP nanomaterials and PANV-CS/TPP nanocomposites.<smiles>COc1cc(OCC2c3cc(C4COc5cc(O)cc(O)c5C4=O)cc(OC)c(=O)c32)cc(OC)c1OC</smiles>

Figure 5. Hypothetical interactions between of CS/TPP and PANV.

\subsection{Thermal Analysis}

The thermal decomposition and stability of CS, CS/TPP, PANV and PANV-CS/TPP are depicted in the simultaneous thermal analyzer (STA)/DTG curves shown in Figure 6A,B. The STA/DTG curve of chitosan (Figure 6A) shows the first thermal event that occurred in the temperature range of 50 to $85^{\circ} \mathrm{C}$ being associated with $27.6 \%$ weight loss assigned to dehydration $[15,21-26]$. The second 
event of thermal decomposition observed from 210 to $390{ }^{\circ} \mathrm{C}$ was associated with $50.1 \%$ weight loss due to degradation of the chitosan polymer. Moreover, a decomposition from 391 to $600{ }^{\circ} \mathrm{C}$ at $2.5 \%$ weight loss is associated with the decomposition of constituting acetic and butyric acids and a series of lower fatty acids [24,25]. Finally, from 600 to $800^{\circ} \mathrm{C}$, a constant curve was observed accomplishing a total loss of $80.4 \%$ of the initial amount. The PANV alone has lower stability than CS and CS/TPP nanomaterials (Figure 6A) that showed comparatively higher stabilities. The STA/DTG curve of CS/TPP (Figure 6A,B) shows the first thermal effect from 50 to $100^{\circ} \mathrm{C}$ being due to the removal of water molecules. The free CS/TPP was thermally stable at temperatures below $200{ }^{\circ} \mathrm{C}$, this being the temperature at which the decomposition of chitosan was observed to occur (Figure 6B). Further decomposition associated with the vaporization and elimination of volatile products was observed around $300{ }^{\circ} \mathrm{C}$ until it reached the final stability, notably from 600 to $800{ }^{\circ} \mathrm{C}[27,28]$. On the other hand, the cross-linking reaction through TPP modified the crystalline nature of chitosan since the decomposition of CS/TPP was reduced to two stages (Figure 6A) compared to the observed three stages for the pure chitosan.
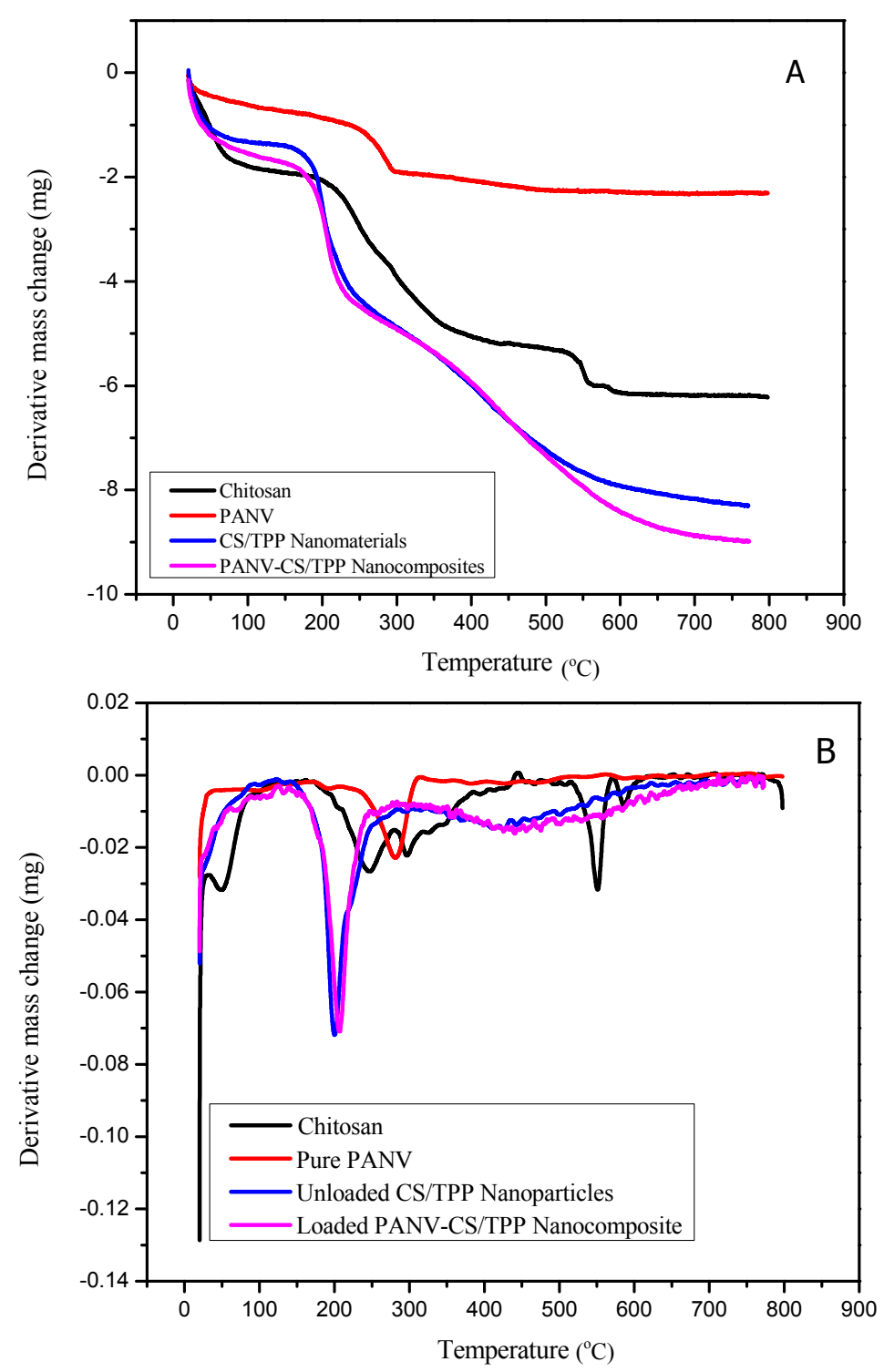

Figure 6. (A) Simultaneous thermal analysis (STA) curves of chitosan, PANV, free CS/TPP nanomaterials and PANV-CS/TPP nanocomposites; (B) Differential thermal gravimetric (DTG) curves of chitosan, PANV, free CS/TPP nanomaterials and PANV-CS/TPP nanocomposites. 
The STA/DTG curve of the PANV-CS/TPP (Figure 6A,B) shows a slight difference in thermal stability compared to the free CS/TPP. After dehydration at $100{ }^{\circ} \mathrm{C}$, PAN-CS/TPP kept decomposing to about $22 \%$ at $196{ }^{\circ} \mathrm{C}$. The final decomposition event was observed from 262 to $600{ }^{\circ} \mathrm{C}$, which is accompanied by the dissociation of pure PANV (Figure 6A).

\subsection{SEM and X-ray Diffraction}

The scanning electron micrographs of pure chitosan showed an uneven and rough surface with a spongy appearance (Figure 7A). The rough surface of the chitosan is attributable to the low degree of deacetylation [29]. The SEM image (Figure 7B) of CS/TPP indicated non-uniform agglomerated particles with no clearly defined morphology. Agglomeration was also vivid when the bioactive compound was encapsulated, leading to the formation of a more compact non-uniform nanoformulation, as shown in the SEM images (Figure 7C,D). The particle sizes of CS/TPP materials ranged from 1.128 to $200 \mu \mathrm{m}$ while those of PANV-CS/TPP nanocomposites had diameters ranging from 0.359 to $12 \mu \mathrm{m}$. The strong interaction caused by inter- and intra-molecular hydrogen bonding between the polyphenol and chitosan during the fabrication of CS/TPP-loaded nanocomposites might have contributed to the observed reduced size of the agglomerated particles (Figure 7C).

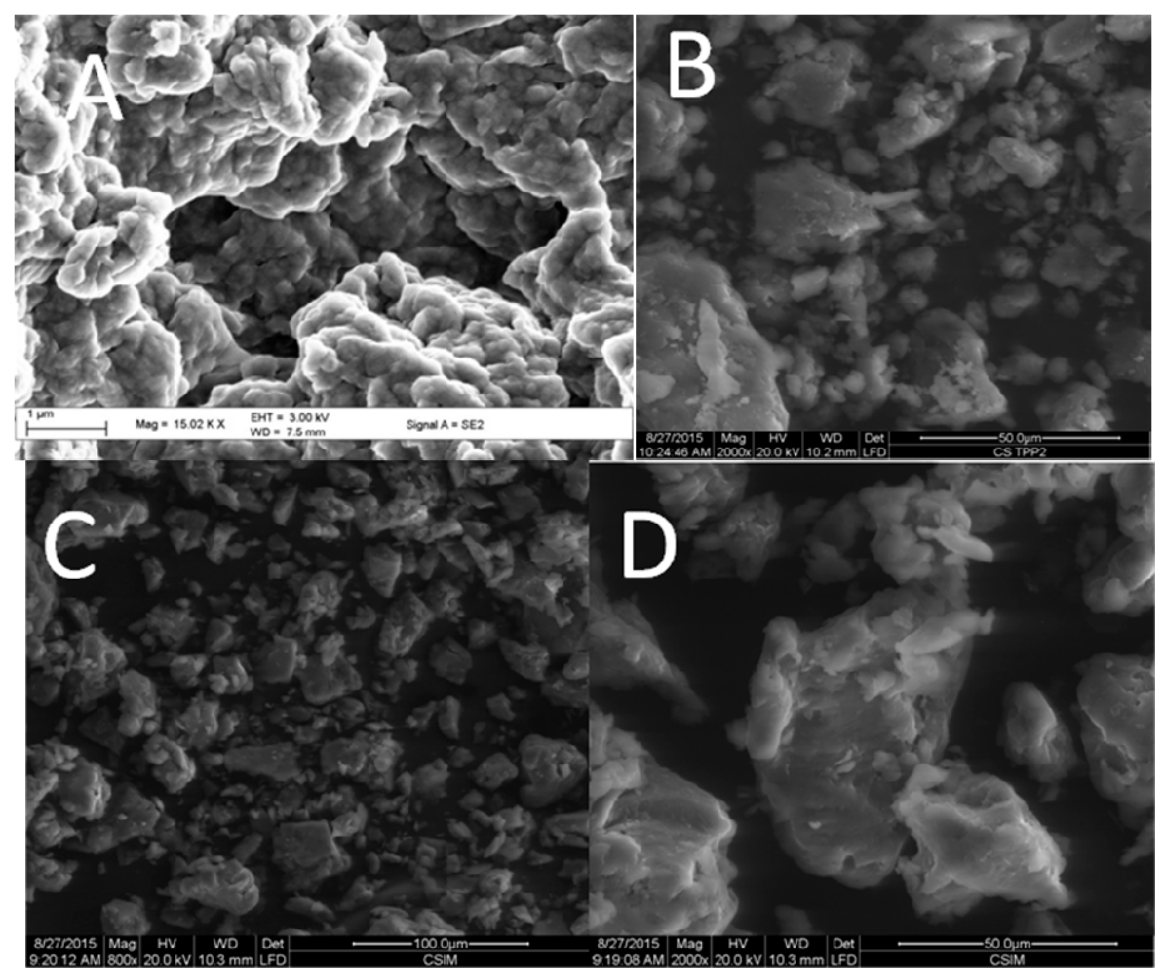

Figure 7. SEM images of (A) chitosan (scale bar $=1 \mu \mathrm{m}) ;($ B $)$ CS/TPP (scale bar $=50 \mu \mathrm{m}$ ); (C) PANV-CS/TPP (scale bar $=100 \mu \mathrm{m})$; and $($ D) PANV-CS $/$ TPP $($ scale bar $=50 \mu \mathrm{m})$.

The powder X-ray diffraction patterns of CS/TPP (Figure 8) depicted the crystalline nature of the particles with intense reflections at $2 \theta=8.15^{\circ}$ and $20.93^{\circ}$, together with minor reflection $2 \theta$ at $30.33^{\circ}$. The XRD of the PANV-CS/TPP nanocomposite was not recorded due to sample limitations. 


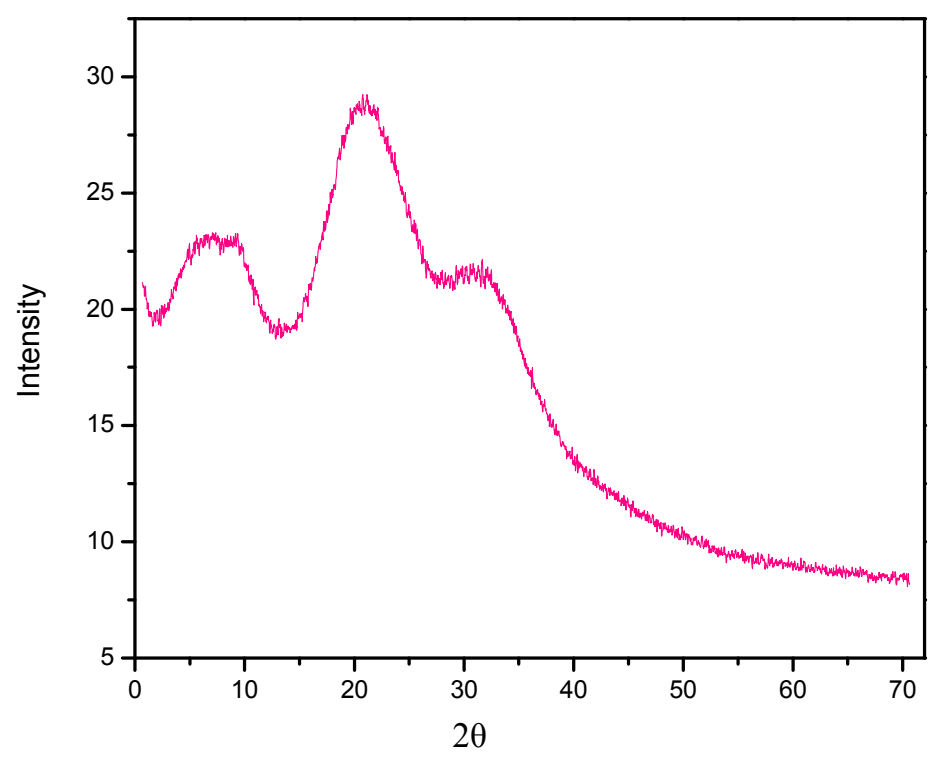

Figure 8. X-ray diffractogram of CS/TPP.

\subsection{Effect of PANV and Chitosan Concentrations on Encapsulation Efficiency}

The effect of the test compound concentrations $(0.04,0.08,0.1$ and $0.2 \mathrm{mg} / \mathrm{mL})$ and chitosan concentrations $(1,2$ and $3 \mathrm{mg} / \mathrm{mL})$ was evaluated to determine the encapsulation efficiency (EE). The results summarized in Figure 9 show that the increase of panchovillin concentrations from 0.04 to $0.2 \mathrm{mg} / \mathrm{mL}$ brought an increased EE under different chitosan concentrations. This effect is interpreted as the outcome of the improved intercalation of the polyphenol into the chitosan network ensuing an activation of hydroxyl sites and establishing stronger hydrogen bonding in the system [30]. A smooth increase in EE was observed when the 1 and $2 \mathrm{mg} / \mathrm{mL}$ chitosan solutions were used as compared to the chitosan solution of a $3 \mathrm{mg} / \mathrm{mL}$ concentration, which indicated a tremendous decrease in EE (Figure 9). This enormous decrease in EE with the increase in chitosan solution concentration might be due to the high viscosity of the gelation medium with a high concentration of chitosan, resulting in a decrease in the liquid phase resistance against dispersion and, hence, forming large nanoparticles and a further decrease in encapsulation [20]. The encapsulation efficiency decreased from $76.24 \%$ to $31.52 \%$ as the CS/TPP mass ratio increased from $2.5: 1$ to $7.5: 1$. Therefore, small CS/TPP ratios of 2.5:1 and 5.0:1 associated with low gelation medium and a low concentration of chitosan solution are suitable for higher encapsulation efficiency than a higher CS/TPP mass ratio of 7.5:1. A similar trend has previously been reported elsewhere [30]. Overall, the CS/TPP ratio of 2.5:1 is the best because it achieves higher EE and, hence, higher concentrations of the polyphenol, panchovillin. However, for further studies that included the in vitro release kinetics, the in vivo antimycobacterial assay and physical characterizations, the 5.0:1 CS/TPP ratio was preferred, for which the EE and loading capacity (LC) were found to be $70.12 \%$ and $0.36 \%$, respectively.

\subsection{In Vitro Release Studies of PANV-CS/TPP}

The in vitro release profile of the PANV-CS/TPP as prepared using the 5.0:1 CS/TPP solution is indicated in Figure 10. The in vitro release profile shows the initial burst of $42 \%$ of the PANV after six hours. The initial burst release is conceived to be due to the poorly-entrapped and adsorbed bioactive compound when it interacts with chitosan during the fabrication of the nanoformulation. The study further concluded that $81 \%$ of PANV was released within $72 \mathrm{~h}$. The burst release observed in the present study at $6 \mathrm{~h}$ (Figure 10) could be desirable for the initial release of a high amount of the bioactive compounds with the ensuing quick and effective availability within $6 \mathrm{~h}$. 


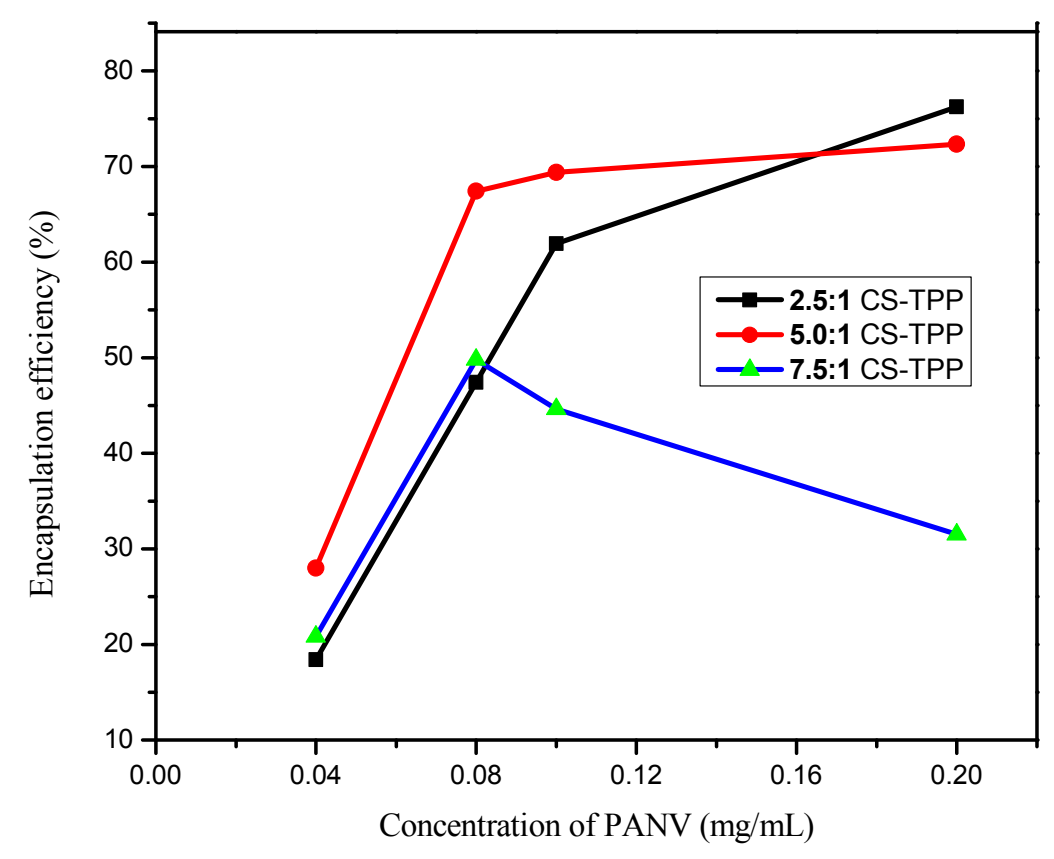

Figure 9. The effect of the PANV concentration on encapsulation efficiency.

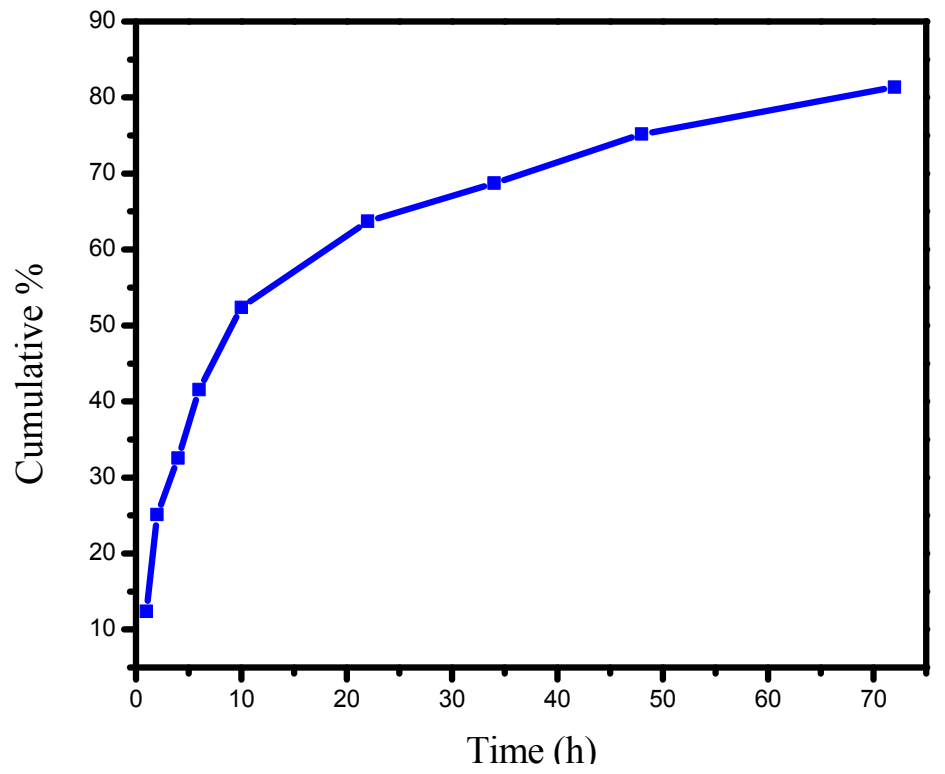

Figure 10. The release profiles of PANV-CS/TPP prepared using a 5.0:1 CS/TPP mass ratio.

\subsection{In Vivo Antimycobacterial Assay}

The in vivo antimycobacterial results are presented in Table 1 and in Figures 11 and 12. The behaviors and effects of larvae treated with PANV and PANV-CS/TPP were observed by comparing with the controls after 24 and $48 \mathrm{~h}$ (Table 1 and Figure 12). The positive control larvae were injected with MIP only, and the body immune system response against the introduced bacteria was observed. The inoculated larvae turned into a black color after ten minutes, indicating the larval immune reaction due to cleavage of prophenoloxidase to activate phenoloxidase that limit the growth of MIP, as similarly reported elsewhere [31]. All of the positive control larvae died and appeared black colored after $24 \mathrm{~h}$ of incubation at $37^{\circ} \mathrm{C}$ (Table 1 and Figure 11A). The death of positive control larvae resulted from body immune response failure to fight against the bacteria. This resulted in the 
extreme growth of bacteria colonies, which were highly concentrated in the cells of the infected larva (Figure 11D). The negative control larvae (Figure 11B) were not injected with bacteria and survived to the end of the study $(48 \mathrm{~h}$ ), proving the absence of infection. This was established beyond a doubt, as their cells were clean and well differentiated as observed under the microscope (at the magnification of $100 \times$ ), indicating the absence of pathogen colonies (Figure 11E). The results obtained when the larvae were injected with free chitosan nanomaterials (Table 1 and Figure 11C,F) showed the larvae to be active throughout the study, manifesting the non-toxicity of chitosan.

Table 1. In vivo antimycobacterial activity of Mycobacterium indicus pranii (MIP)-infected Galleria mellonella larvae.

\begin{tabular}{ccccc}
\hline \multirow{2}{*}{ Compound Dose } & \multicolumn{2}{c}{$\mathbf{2 4} \mathbf{h}$} & \multicolumn{2}{c}{$\mathbf{4 8} \mathbf{~}$} \\
\cline { 2 - 5 } & Dead (\%) & Alive (\%) & Dead (\%) & Alive (\%) \\
\hline PANV $\left(80 \mathrm{nM} / \mathrm{mg} \mathrm{bw}^{*}\right)$ & 14 & 86 & 29 & 71 \\
PANV-CS/TPP $\left(0.289 \mathrm{nM} / \mathrm{mg} \mathrm{bw}^{*}\right)$ & 20 & 80 & 60 & 40 \\
CS/TPP & 0 & 100 & 0 & 100 \\
\hline
\end{tabular}

${ }^{*}$ bw $=$ body weight.
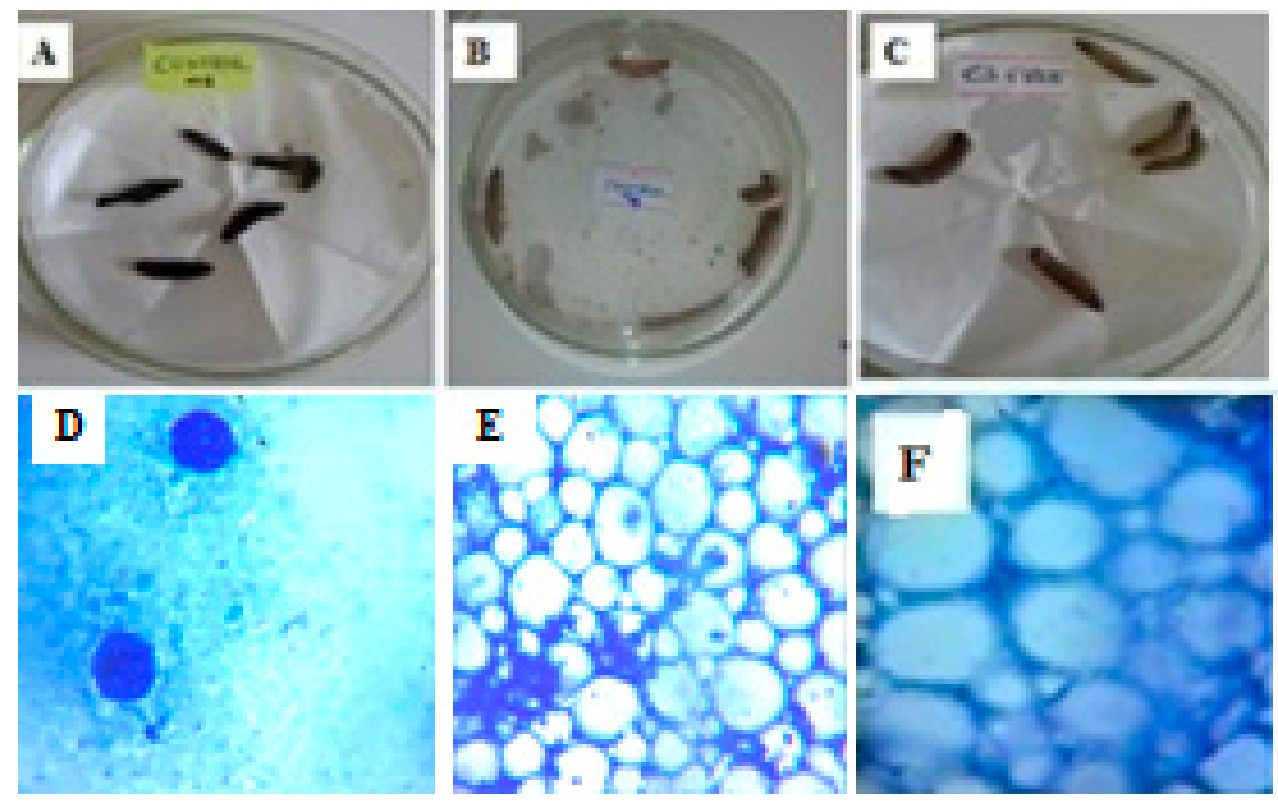

Figure 11. (A,D) Infected larvae (Positive control) and their appearance under the microscope at the magnification of $100 \times$; (B,E) Non-infected Larvae (Negative control) and their appearance under the microscope at the magnification of $100 \times ;(\mathbf{C}, \mathbf{F})$ Larvae injected with Free CS/TPP and their appearance under the microscope at the magnification of $100 \times$.

The in vivo antimycobacterial results of PANV and PANV-CS/TPP were slightly different (Table 1 and Figure 12). This was further confirmed statistically, whereby after $24 \mathrm{~h}$, the difference between the larvae treated with PANV and PANV-CS/TPP was not significant at $p<0.05$ ( $\chi^{2}$-statistcs of 1.2757, $p$-value $=0.258$ ). However, a clear difference was observed after 48 hours, whereby PANV prolonged the life of larvae by $70 \%$ compared to the PANV-CS/TPP. The difference between the two treatment was statistically significant at $p<0.05$ with the $\chi^{2}$-statistcs of 19.455 and $p$-value $=0.00001$. 

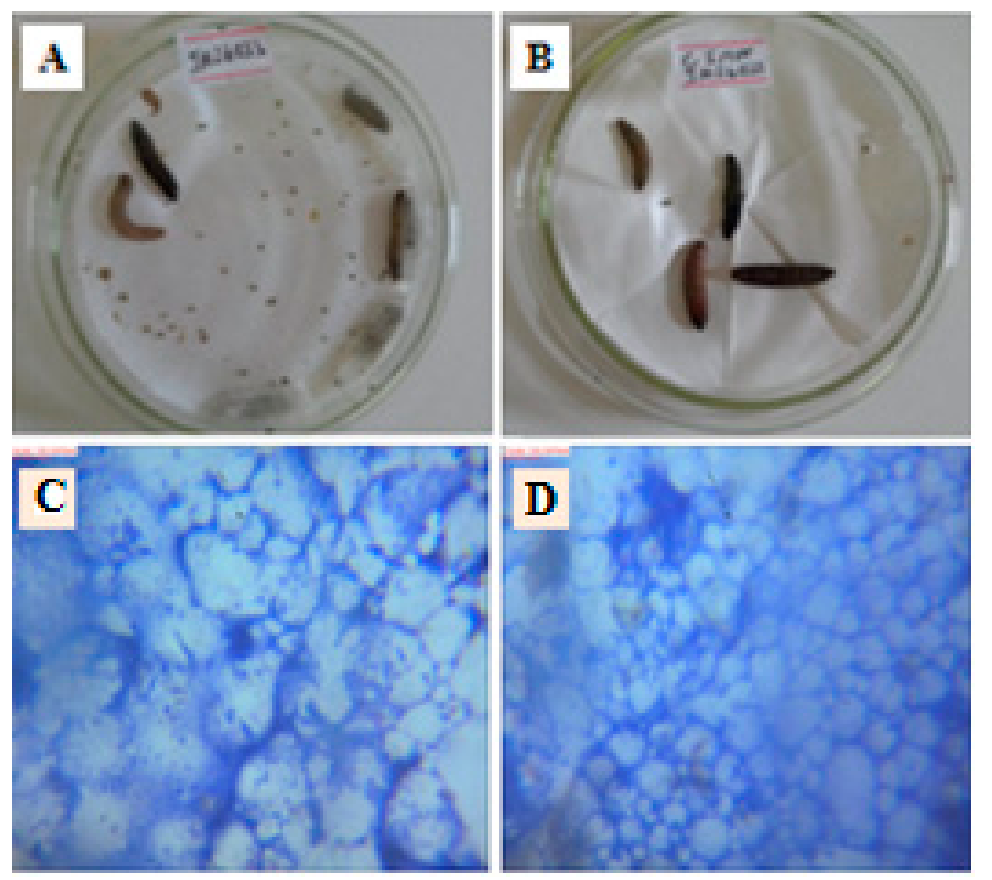

Figure 12. (A) Larva treated with the PANV and their appearance under the microscope at the magnification of $100 \times(\mathbf{C})$; (B) Larva treated with the PANV-CS/TPP nanocomposites and their appearance under the microscope at the magnification of $100 \times(\mathbf{D})$.

Furthermore, the clearance of bacteria colony density as observed in Figure 12C,D compared to the positive control in Figure 11D and the negative control in Figure 11E indicates that the PANV retained its antimycobacterial efficacies, even when applied to an in vivo system. This is contrary to most natural products that tend to lose their efficacies in in vivo models [32]. It is important to note that the amount of free PANV tested was far higher than the amount of PANV loaded on CS/TPP. The concentration of encapsulated PANV injected into the infected larva was just $0.289 \mathrm{nM} / \mathrm{mg}$ body weight compared to free PANV, which was $80 \mathrm{nM} / \mathrm{mg}$ body weight. Therefore, although PANV appeared to be more efficacious than PANV-CS/TPP, still, the latter was relatively more efficacious than the former. This assay has thus proven that the efficacy of PANV was indeed enhanced when encapsulated in the CS nanomaterials.

\section{Materials and Methods}

\subsection{Test Organisms}

The non-pathogenic Mycobacterium indicus pranii (MIP) strain DSM 45239 supplied by DSMZ (The Germany Resource Centre for Biological Materials, Braunschweig, Germany) was used to determine of anti-mycobacterial properties of the free panchovillin and panchovillin-loaded chitosan nanocomposites.

\subsection{Reagents and Other Materials}

All chemicals and reagents used were of analytical grade. The pure compound panchovillin (Figure 1) was isolated from Erythrina schliebenii in a previous study [12]. Chitosan (molecular weight $20.2 \mathrm{kDa}$, degree of $\mathrm{N}$-deacetylation $73.5 \%$ ) was obtained by deacetylation of chitin extracted from the waste shrimp (Litopenaeus vannamei) shells collected from Dar es Salaam Fish Market at Kivukoni, Dar es Salaam, Tanzania. Tripolyphosphate (TPP) was purchased from Sigma-Aldrich (Stockholm, Sweden) and used without further purification. 


\subsection{Sample Collection}

The shrimps (Litopenaeus vannamei) were the source of the collected shell waste materials. The shells $(15 \mathrm{~kg})$ were sorted and thoroughly washed with running tap water to remove sand and other impurities. The cleaned shells were dried under the sun for three days affording $290 \mathrm{~g}$ of the dried shells. The shells were then ground to afford $286 \mathrm{~g}$ of fine powder.

\subsection{Purification of Chitin}

Purification of chitin was carried out in three steps, namely, deproteination, demineralization and decolorization, following the reported procedure with some few modifications [33,34]. In a typical experiment, $100 \mathrm{~g}$ of fine powdered shells were demineralized by slowly adding $20 \% \mathrm{HCl}$ at a ratio of $1 \mathrm{~g}$ per $14 \mathrm{~mL}(w / v)$. The mixture was stirred at room temperature until no evolution of gas was observed. The mixture was then filtered and washed with distilled water to a neutral $\mathrm{pH}$. The demineralized powder $(60 \mathrm{~g})$ was deproteinated using $1 \mathrm{M} \mathrm{NaOH}$ added at the ratio of $1 \mathrm{~g}$ per $10 \mathrm{~mL}(w / v)$. The mixture was then heated with continuous stirring at $70{ }^{\circ} \mathrm{C}$ for $24 \mathrm{~h}$ and then washed with distilled water until neutral to obtain $41 \mathrm{~g}$ of crude chitin. The crude chitin obtained was decolorized by soaking in $1 \% \mathrm{KMnO}_{4}$ for $1 \mathrm{~h}$ followed by $1 \% \mathrm{H}_{2} \mathrm{C}_{2} \mathrm{O}_{4} \cdot 2 \mathrm{H}_{2} \mathrm{O}$ at $60{ }^{\circ} \mathrm{C}$ for $1 \mathrm{~h} \mathrm{[35]}$. The mixture was finally washed with distilled water and dried at $60^{\circ} \mathrm{C}$ to obtain $40 \mathrm{~g}$ of pure chitin.

\subsection{Preparation of Chitosan by N-Deacetylation of Chitin}

Chitosan (CS) was prepared by using the already established methods, albeit with minor modifications [33,34,36,37]. Typically, $20 \mathrm{~g}$ of chitin were soaked in $200 \mathrm{~mL}$ of $50 \% \mathrm{NaOH}$ and heated at $116{ }^{\circ} \mathrm{C}$ for $5 \mathrm{~h}$. The mixture was then cooled, and $300 \mathrm{~mL}$ of distilled water were added and left to stand overnight. This was followed by filtration, and the residue was washed with distilled water until neutral to obtain $11 \mathrm{~g}$ of crude chitosan. The crude chitosan $(11 \mathrm{~g})$ was then dissolved in $250 \mathrm{~mL}$ of $1 \% \mathrm{CH}_{3} \mathrm{COOH}(\mathrm{pH} 3.03)$, and the insoluble materials were removed to give a clear supernatant that was neutralized with $2 \mathrm{M} \mathrm{NaOH}$, washed to neutral $\mathrm{pH}$ and dried at $60{ }^{\circ} \mathrm{C}$ giving $9 \mathrm{~g}$ of pure chitosan that was transferred to vials and stored in the refrigerator until required for further analysis and application. The solubility of the obtained chitosan was tested in $1 \% \mathrm{CH}_{3} \mathrm{COOH}$ by stirring at $1000 \mathrm{rpm}$ under room temperature for $30 \mathrm{~min}$.

\subsection{Preparation of CS/TPP and PANV-CS/TPP Nanocomposites}

Chitosan nanomaterials were synthesized through the ionotropic gelation of chitosan with tripolyphosphate (TPP) [19,38,39]. In an experiment, chitosan was dissolved in acetic acid aqueous solution to give three different concentrations namely, $1 \mathrm{mg} / \mathrm{mL}$ (prepared by dissolving $5 \mathrm{mg}$ of chitosan in $5 \mathrm{~mL}$ of acetic acid), $2 \mathrm{mg} / \mathrm{mL}$ (prepared by dissolving $10 \mathrm{mg}$ of chitosan in $5 \mathrm{~mL}$ of acetic acid) and $3 \mathrm{mg} / \mathrm{mL}$ (prepared by dissolving $15 \mathrm{mg}$ of chitosan in $5 \mathrm{~mL}$ of acetic acid). The concentration of acetic acid in all cases was kept 1.75 times higher than that of chitosan [38]. Furthermore, $2 \mathrm{~mL}$ of the $1 \mathrm{mg} / \mathrm{mL}$ solution of sodium tripolyphosphate (prepared by dissolving $2 \mathrm{mg}$ of TPP in $2 \mathrm{~mL}$ of distilled water) were added dropwise to $5 \mathrm{~mL}$ of each of the aforementioned concentrations of chitosan solution under continuous stirring at $1000 \mathrm{rpm}$ for $1 \mathrm{~h}$ at room temperature $[19,40]$. This led to a spontaneous fabrication of chitosan sols. The nanostructured sols were then separated by centrifugation to afford nanostructured chitosan that was freeze-dried, weighed and stored in a refrigerator until required. The PANV-CS/TPP nanocomposites were similarly prepared by ionotropic gelation of CS/TPP with chitosan solutions of 1,2 and $3 \mathrm{mg} / \mathrm{mL}$ being prepared separately [19,38]. The encapsulation of PANV was achieved using 2.5:1, 5.0:1 and 7.5:1 CS/TPP mass ratios to establish the effective CS/TPP ratio that would give better encapsulation efficiency. For further studies, such as the in vitro release kinetics, the in vivo antimycobacterial assay and physical characterizations, PANV-CS/TPP nanocomposites were prepared using the 5.0:1 CS/TPP mass ratio. 


\subsection{Effect of PANV and Chitosan Concentrations on Encapsulation Efficiency}

The study on the effect of panchovillin concentration on encapsulation efficiency using different concentrations $(1,2$ and $3 \mathrm{mg} / \mathrm{mL})$ of chitosan solution was investigated. Firstly, the blank supernatant chitosan nanomaterials for each chitosan concentration were prepared using $1 \mathrm{mg} / \mathrm{mL}$ TPP to serve as the controls during encapsulation. Different concentrations $(0.04,0.08,0.1$ and $0.2 \mathrm{mg} / \mathrm{mL})$ of PANV were separately prepared and added dropwise to each of the chitosan concentrations. The solution was then stirred at $1000 \mathrm{rpm}$ for $30 \mathrm{~min}$ to enhance the homogeneity. To prepare PANV-CS/TPP nanocomposites, the crosslinking agent, that is TPP solution $(1 \mathrm{mg} / \mathrm{mL})$, was added dropwise to the solution containing chitosan and the test compound. The mixture was continuously stirred at $1000 \mathrm{rpm}$ for $1 \mathrm{~h}$ under room temperature. Finally, the supernatant containing the free compound was centrifuged at $3500 \mathrm{rpm}$ for $30 \mathrm{~min}$ and filtered using $125 \mathrm{~mm}$ filter paper to obtain a clear solution. The effects of the PANV concentrations at different concentrations of chitosan were then studied using a UV-vis spectrophotometer.

\subsection{Encapsulation of PANV for Bioassay Using Chitosan Solution}

The $2 \mathrm{mg} / \mathrm{mL}$ chitosan solution was selected for encapsulation of PANV. The PANV-CS/TPP nanocomposites were obtained through the established protocol [19]. The resulting PANV-CS/TPP nanocomposites were centrifuged at $3500 \mathrm{rpm}$ for $30 \mathrm{~min}$ under room temperature. The supernatant containing free PANV was collected and filtered using $125 \mathrm{~mm}$ filter paper to acquire a clear solution. The clear supernatant solution was analyzed using the UV-vis spectrophotometer to quantify the free compound. The nanocomposites collected were mixed with pure water and re-centrifuged. The supernatant obtained was further analyzed using the UV-vis spectrophotometer for the presence of free natural product. The supernatant was discarded if the natural product was not detected. The nanocomposites obtained were freeze-dried, weighed and stored for characterization, the in vitro release and in vivo antimycobacterial studies.

\subsection{Encapsulation Efficiency and Loading Capacity}

The encapsulation efficiency (EE) of the nanomaterials is the amount of the test compound entrapped in the nanomaterials. It is calculated by taking the ratio of the amount of test compound in the nanomaterials to the amount of the initial total amount of the test compound multiplied by $100 \%$ (Equation (1)). The loading capacity (LC) of nanomaterials, on the other hand, is the ability of the nanomaterials to entrap the test compound. The latter is calculated by taking the ratio of the amount of the active compound entrapped to the amount of the nanoformulation multiplied by $100 \%$ (Equation (2)) [19,38,41,42]. The process of encapsulation was carried out using $2 \mathrm{mg} / \mathrm{mL}$ and $0.1 \mathrm{mg} / \mathrm{mL}$ of chitosan and PANV, respectively.

$$
\begin{aligned}
& \mathrm{EE}=\frac{\text { Total amount of } X-\text { Free amount of } X}{\text { Total amount of } X} \times 100 \% \\
& \mathrm{LC}=\frac{\text { Total amount of } X-\text { Free amount of } X}{\text { Weight of nanoformulation }} \times 100 \%
\end{aligned}
$$

where $X$ is the test compound under investigation.

\subsection{In Vitro Release Studies}

The PANV-CS/TPP (22 mg) containing about $0.1008 \mathrm{mg}$ of panchovillin was suspended in a glass bottle containing $100 \mathrm{~mL}$ of the receiving medium at $\mathrm{pH}$ 7.4. The medium was composed of phosphate-buffered saline (PBS) solution containing $10 \%$ ethanol to enhance the solubility of the test compound [43-45]. The mixture was then stirred and incubated at $37^{\circ} \mathrm{C}[19,38]$. At appropriate time intervals $(1,2,4,6,10,22,34,48$ and $72 \mathrm{~h}), 5 \mathrm{~mL}$ of the sample were withdrawn from the receptor medium and centrifuged at $3500 \mathrm{rpm}$ for $30 \mathrm{~min}$ while maintaining the sink condition by 
replacing the removed sample with fresh medium [19,44,45]. The amount of the test compound released in the supernatant was evaluated using the UV-vis spectrophotometer at a $295 \mathrm{~nm}$ wavelength of maximum absorption. The profile for cumulative percentage of in vitro release was plotted using Equation (3) [46].

$$
\% \text { Release }=\frac{\text { Released PANV }}{\text { Initial PANV }} \times 100
$$

\subsection{In Vivo Antimycobacterial Bioassay Using Galleria Mellonella}

The sub-culturing of MIP followed the standard procedure [47]. The G. mellonella larvae were inoculated with the sub-cultured MIP by injecting into the hemocoel through the final pro-leg. Bacterial inoculums were prepared from five-day grown cultures in Middlebrook 7H9 broth base containing $0.1 \%$ Tween 80 , and the turbidity was adjusted to the equivalent of $0.5 \mathrm{McF}$ arland units (approximately $1.2 \times 10^{8} \mathrm{CFU} / \mathrm{mL}$ ). The injection was carried out by opening the last left pro-leg while softly applying pressure to the sides of the larva's body. The aperture following injection was re-sealed after the removal of the syringe, which led to imperceptible indication of the damage. Incubation was done at the temperature of $37^{\circ} \mathrm{C}$ with respect to the controls in order to study the effect of both free PANV and PANV-CS/TPP. The G. mellonella larvae were then observed after 24 and $48 \mathrm{~h}$. To investigate further the effect of test bioactive compound on the growth of MIP in the larva's body, the G. mellonella larvae were dissected, and the images were developed to assess the effect of treatment with respect to the controls.

\subsection{Characterization of Materials}

Infra-red (IR) spectra were recorded on the Alpha FTIR spectrometer from Bruker Optic GmgH, equipped with an ATR platinum crystal. The spectrometer was set to perform a total of 25 scans on each sample in the range of 500 to $4000 \mathrm{~cm}^{-1}$. The absorption peaks generated during analysis were used for the identification of the structural features of the materials and for the determination of the degree of deacetylation (DD) of the prepared chitosan. The degree of deacetylation was determined by the computation Equation (4) with the amide I probe absorption band and the hydroxyl reference band of 1651 and $3361 \mathrm{~cm}^{-1}$, respectively [48].

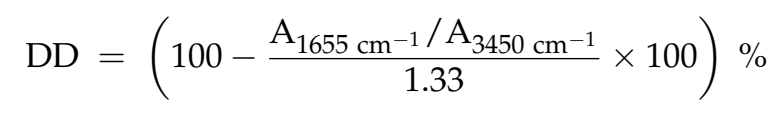

Absorption spectra were recorded on a Shimadzu UV/vis-240 spectrophotometer in the range of 200 to $800 \mathrm{~nm}$. The molecular weight of the purified chitosan was determined using MALDI-TOF-MS analysis. The tetrahydrofuran (THF) solution of the chitosan sample and trans-2-[3-(4-tert-butylphenyl)-2-methyl-2-propylidene] malononitrile (DCTB) matrix (1:10 v/v) were mixed in an Eppendorf tube. Then, $0.5 \mu \mathrm{L}$ of the resulting solution was deposited on two spots on the stainless microtiter format MALDI target and dried at room temperature to produce a solid layer. The MALDI-TOF mass spectrum of chitosan was acquired by 500 laser shots by autoflex when the instrument was operating in the positive ion linear (flight path $1.22 \mathrm{~m}$ ) mode with an acceleration voltage of $20.04 \mathrm{kV}$ [49].

The XRD analysis was used to characterize the crystalline nature of the chitosan nanostructure. The sample was ground in an agate mortar, resulting in a powder, which was then loaded on the sample holder, compressed and levelled before being subjected for X-ray diffraction analysis. The $\mathrm{X}$-rays generated by a copper anode source were filtered to produce monochromatic radiation that was directed to the sample. Throughout the analysis, the spectra were recorded using $\mathrm{CuK} \alpha$ radiation and the $2 \theta$ sampling technique. The voltage and current of $40 \mathrm{kV}$ and $40 \mathrm{~mA}$, respectively, were set for the sample analysis, and the scan range was $2^{\circ}$ to $70^{\circ}$ with a step size of $0.07^{\circ}$. The time, 10 s per step, was set, and the sample analysis was completed after three hours. The sample XRD patterns' data generated were processed using Philips texture software as a pole figure and orientation distribution functions (ODF). The thermal behavior of the prepared materials was determined using the Linseis 
STP PT-1000 simultaneous thermal analyzer (STA). The samples for analysis were finely ground, and $6 \mathrm{mg}$ of the sample in each analysis were put in the fused alumina, $\mathrm{Al}_{2} \mathrm{O}_{3}$ sample holder and analyzed at the temperature range of 50 to $800{ }^{\circ} \mathrm{C}$ at the heating rate of $5{ }^{\circ} \mathrm{C} / \mathrm{min}$. The results were plotted with temperature and mass loss. The surface morphology analysis of chitosan, CS/TPP and PAN-CS/TPP materials was performed by using a Zeiss Ultra plus FEG scanning electron microscopy (SEM) and the LEO Ultra 55 SEM.

\section{Conclusions}

The polyphenol panchovillin was encapsulated into the CS/TPP framework by ionotropic gelation. FTIR analysis indicated a successful entrapment of PANV in the nanomaterial. The thermal stability of the nanocomposite was enhanced to $200{ }^{\circ} \mathrm{C}$ compared to the pure panchovillin, whose decomposition occurred at $262{ }^{\circ} \mathrm{C}$. The in vitro release profile of panchovillin from the CS/TPP nano-framework was initially fast, up to $42 \%$ after six hours, and was followed by a slow release, thereby reaching the maximum release of $81 \%$ after $72 \mathrm{~h}$. The in vivo antimycobacterial activity of the pure PANV and the PANV-CS/TPP nanocomposites was comparable at $24 \mathrm{~h}$ but different at $48 \mathrm{~h}$. However, it should be noted that the concentration of the bioactive compound in PANV-CS/TPP nanocomposites injected into the larvae was remarkably low $(0.289 \mathrm{nM} / \mathrm{mg} \mathrm{bw})$, hence proving that the efficacy of PANV was indeed enhanced when encapsulated in the CS nanomaterials. Thus, the results observed in this study are a benchmark for similar studies aiming at improving the efficacy of bioactive natural products.

Acknowledgments: The study was supported by the International Foundation for Science (IFS) Grant No. J/5528-1. We are grateful to Aston University (UK), Gothenburg University (Sweden), Chalmers University of Science and Technology (Sweden), the University of Zululand (South Africa), the Institute of Traditional Medicine (Tanzania) and the National Institute for Medical Research, Ngongongare Medical Research Center, Arusha (Tanzania), for assistance with some of the analyses.

Author Contributions: Joan J. E. Munissi, Paul Erasto and Egid B. Mubofu conceived of and designed the experiments. Edward Rwegasila, Paul Erasto and Joan J. E. Munissi performed the experiments. All authors analyzed the data. Joan J. E. Munissi, Paul Erasto and Stephen S. Nyandoro contributed reagents and other research materials. All authors contributed equally to preparation of the manuscript.

Conflicts of Interest: The authors declare no conflict of interest.

\section{References}

1. Bharali, D.J.; Siddiqui, I.A.; Adhami, V.M.; Chamcheu, J.C.; Aldahmash, A.M.; Mukhtar, H.; Mousa, S.A. Nanoparticle delivery of natural products in the prevention and treatment of cancers: Current status and future prospects. Cancers 2011, 3, 4024-4045. [CrossRef] [PubMed]

2. Ranjita, S.; Loaye, A.; Khalil, M. Present status of nanoparticle research for treatment of tuberculosis. J. Pharm. Sci. 2011, 14, 100-116.

3. Sun, D.; Zhuang, X.; Xiang, X.; Liu, Y.; Zhang, S.; Liu, C.; Barnes, S.; Grizzle, W.; Miller, D.; Zhang, H.A. Novel nanoparticle drug delivery system: The anti-inflammatory activity of curcumin is enhanced when encapsulated in exosomes. Mol. Ther. 2010, 18, 1606-1614. [CrossRef] [PubMed]

4. Ochekpe, N.A.; Olorunfemi, P.O.; Ngwuluka, N.C. Nanotechnology and drug delivery part 2: Nanostructures for drug delivery. Trop. J. Pharm. Res. 2009, 8, 275-287. [CrossRef]

5. Dhillon, G.S.; Kaur, S.; Sarma, S.J.; Brar, S.K.; Verma, M.; Surampalli, R.Y. Recent development in applications of important biopolymer chitosan in biomedicine, pharmaceuticals and personal care products. Curr. Tissue Eng. 2013, 2, 20-40. [CrossRef]

6. Zhang, H.; Wu, S.; Tao, Y.; Zang, L.; Su, Z. Preparation and characterization of water soluble chitosan nanoparticles as protein delivery system. J. Nanomater. 2009, 2010, 1-6. [CrossRef]

7. World Health Organization. Global Tuberculosis Report. 2013. Available online: http://www.who.int/iris/ bitstream/10665/91355/1/9789241564656_eng.pdf (accessed on 1 April 2015).

8. Thangapazham, R.L.; Puri, A.; Tele, S.; Blumenthal, R.; Maheshwari, R.K. Evaluation of a nanotechnology-based carrier for delivery of curcumin in prostate cancer cells. Int. J. Oncol. 2008, 32, 1119-1123. [CrossRef] [PubMed] 
9. Bueno, J.; Coy, E.D.; Stashenko, E. Antimycobacterial natural products-An opportunity for the colombian biodiversity. Rev. Esp. Quimioter. 2011, 24, 175-183. [PubMed]

10. Soto, M.L.; Falqué, E.; Domínguez, H. Relevance of natural phenolics from grape and derivative products in the formulation of cosmetics. Cosmetics 2015, 2, 259-276. [CrossRef]

11. Clarke, G.P.; Burgess, N.D.; Mbago, F.M.; Mligo, C.; Mackinder, B.; Gereau, R.E. Two "extinct" trees rediscovered near Kilwa, Tanzania. J. East Afr. Nat. Hist. 2011, 100, 133-140. [CrossRef]

12. Nyandoro, S.S.; Munissi, J.J.E.; Kombo, M.; Mgina, C.A.; Fangfang, P.; Gruhonjic, A.; Fitzpatrick, P.; Landberg, G.; Lu, Y.; Wang, B.; et al. Flavonoids from Erythrina schliebenii. J. Nat. Prod. 2016. under preparation.

13. Adochitei, A.; Drochioiu, G. Rapid Characterization of peptide secondary structure by FT-IR spectroscopy. Rev. Roum. Chim. 2010, 56, 783-791.

14. Kamala, K.; Sivaperumal, P.; Rajaram, R. Extraction and characterization of water soluble chitosan from parapeneopsis stylifera shrimp shell waste and its antibacterial activity. Int. J. Sci. Res. Pub. 2013, 3, 1-8.

15. Ujang, Z.; Diah, M.; Rashid, A.H.A.; Halim, A.S. The development, characterization and application of water soluble chitosan. Biotechnol. Biopolym. 2011, 2011, 1-23.

16. Zhang, A.; Qin, Q.; Zhang, H.; Wang, H.; Li, X.; Miao, L.; Wu, Y. Preparation and characterisation of food-grade chitosan from housefly larvae. Czech. J. Food. Sci. 2011, 29, 616-623.

17. Wanule, D.; Balkhande, J.V.; Ratnakar, P.U.; Kulkarni, A.N.; Bhowate, C.S. Extraction and ftir analysis of chitosan from american cockroach, periplaneta americana. Int. J. Eng. Sci. Innov. Technol. 2014, 3, $299-304$.

18. Mohanasrinivasan, V.; Mishra, M.; Paliwal, J.S.; Singh, S.K.; Selvarajan, E.; Suganthi, V.; Devi, C.S. Studies on heavy metal removal efficiency and antibacterial activity of chitosan prepared from shrimp shell waste. J. Biotechnol. 2014, 4, 167-175. [CrossRef]

19. Mohammadpour, D.N.; Eskandari, R.; Avadi, M.R.; Zolfagharian, H.; Mir Mohammad, S.A.; Rezayat, M. Preparation and in vitro characterization of chitosan nanoparticles containing Mesobuthus eupeus scorpion venom as an antigen delivery system. J. Venom. Anim. Toxins Incl. Trop. Dis. 2012, 18, 44-52.

20. Vimal, S.; Taju, G.; Nambi, K.S.N.; Majeed, S.A.; Babu, V.S.; Ravi, M.; Hameed, A.S.S. Synthesis and characterization of CS/TPP nanoparticles for oral delivery of gene in fish. Aquacult 2012, 2012, 14-22. [CrossRef]

21. Peniche-Covas, C.; Argiielles-Monai, W.; Roman, S.J. A kinetic study of the thermal degradation of chitosan and a mercaptan derivative of chitosan. Polym. Degrad. Stab. 1993, 39, 21-28. [CrossRef]

22. Neto, C.G.T.; Giacometti, J.A.; Job, A.E.; Ferreira, F.C.; Fonseca, J.L.C.; Pereira, M.R. Thermal analysis of chitosan based networks. Carbohydr. Polym. 2005, 62, 97-103. [CrossRef]

23. Elhefian, E.A.; Nasef, M.M.; Yahaya, A.H. Preparation and characterization of chitosan/agar blended films: Part 2. Thermal, mechanical, and surface properties. J. Chem. 2012, 9, 510-516. [CrossRef]

24. Puchalska, A.; Mucha, M. Thermogravimetry of chitosan with nanofillers. Prog. Chem. Appl. Chitin 2011, 16, 31-42.

25. Pieróg, M.; Czubenko, J.O.; Drużyńska, M.G. Thermal degradation of double crosslinked hydrogel chitosan membranes. Prog. Chem. Appl. Chitin 2012, 17, 67-74.

26. Gallego, R.; Arteaga, J.F.; Valencia, C.; Franco, J.M. Isocyanate-functionalized chitin and chitosan as gelling agents of castor oil. Molecules 2013, 18, 6532-6549. [CrossRef] [PubMed]

27. Rejinold, N.S.; Muthunarayanan, M.; Muthuchelian, K.; Chennazhi, K.P.; Nair, S.V.; Jayakumar, R. Saponin-loaded chitosan nanoparticles and their cytotoxicity to cancer cell lines in vitro. Carbohydr. Polym. 2010, 84, 407-416. [CrossRef]

28. Parida, U.K.; Rout, N.; Bindhani, B.K. In vitro properties of chitosan nanoparticles induce apoptosis in human lymphoma SUDHL-4 cell line. Adv. Biosci. Biotechnol. 2013, 4, 1118-1127. [CrossRef]

29. Pandey, R.; Khuller, G.K. Solid lipid particle-based inhalable sustained drug delivery system against experimental tuberculosis. Tuberculosis 2005, 85, 227-234. [CrossRef] [PubMed]

30. Stoica, R.; Şomoghi, R.; Ion, R.M. Preparation of chitosan-tripolyphosphate nanoparticles the encapsulation of polyphenols extracted from rose hips. Dig. J. Nanomater. Biostruct. 2013, 8, 955-963.

31. Cook, S.M.; McArthur, J.D. Developing Galleria mellonella as a model host for human pathogens. Med. Health Sci. 2013, 4, 350-353.

32. Abourashed, E.A. Bioavailability of plant-derived antioxidants. Antioxidants 2013, 2, 309-325. [CrossRef] [PubMed] 
33. Islam, M.M.; Masum, S.M.; Rahman, M.M.; Molla, M.A.I.; Shaikh, A.A.; Roy, S.K. Preparation of chitosan from shrimp shell and investigation of its properties. Int. J. Basic Appl. Sci. 2011, 11, 116-130.

34. Ploydee, E.; Chaiyanan, S. Production of high viscosity chitosan from biologically purified chitin isolated by microbial fermentation and deproteinization. Int. J. Polym. Sci. 2014, 2014, 1-8. [CrossRef]

35. Akhtar, N.; Tahir, H.; Sultan, M.; Yasmeen, G.; Hameed, U. Application of chitosan padded rice and wheat husk for the removal of reactive dye from aqueous solution. Afr. J. Biotechnol. 2012, 11, 2756-12765.

36. Puvvada, Y.S.; Vankayalapat, S.; Sukhavasi, S. Extraction of chitin and chitosan from exoskeleton of shrimp for application in the pharmaceutical industry. Int. Curr. Pharm. J. 2012, 1, 258-263. [CrossRef]

37. Mirzadehl, H.; Yaghobi, N.; Amanpour, S.; Ahmadi, H.; Mohagheghi, M.A.; Hormozi, F. Preparation of chitosan derived from shrimp's shell of persian gulf as a blood hemostasis agent. Iran Polym. J. 2002, 11, 63-68.

38. Calvo, P.; Remunan-Lopez, C.; Vila-Jato, J.L.; Alonso, M.J. Novel hydrophilic chitosan-polyethylene oxide nanoparticles as protein carriers. J. Appl. Polym. Sci. 1997, 63, 125-132. [CrossRef]

39. Vimal, S.; Majeed, S.A.; Taju, G.; Nambi, K.S.N.; Raj, N.S.; Madan, N.; Farook, M.A.; Rajkumar, T.; Gopinath, D.; Hameed, A.S.S. Chitosan tripolyphosphate (CS/TPP) nanoparticles: Preparation, characterization and application for gene delivery in shrimp. Acta Trop. 2013, 128, 486-493. [CrossRef] [PubMed]

40. Zhao, L.; Shi, L.; Zhang, Z.; Chen, J.; Shi, D.; Yang, J.; Tang, Z. Preparation and application of chitosan nanoparticles and nanofibers. Braz. J. Chem. Eng. 2011, 28, 353-362. [CrossRef]

41. Ponnuraj, R.; Janakiraman, K.; Gopalakrishnan, S.; Senthilnathan, K.; Meganathan, V.; Saravanan, P. Formulation and characterization of epigallocatechin gallate nanoparticles. Am. J. Pharm. Res. 2015, $5,387-399$.

42. Cover, N.F.; Yuen, S.L.; Parsons, A.K.; Kumar, A. Synergetic Effects of doxycycline-loaded chitosan nanoparticles for improving drug delivery and efficacy. Int. J. Nanomed. 2012, 7, 2411-2419.

43. Nathiya, S.; Durga, M.; Devasena, T. Preparation, physico-chemical characterization and biocompatibility evaluation of quercetin loaded chitosan nanoparticles and its novel potential to ameliorate monocrotophos induced toxicity. Dig. J. Nanomater. Biostruct. 2014, 9, 1603-1614.

44. Anbarasan, B.; Menon, V.V.; Niranjana, V.A.; Ramaprabhu, S. Optimization of the formulation and in-vitro evaluation of chloroquine loaded chitosan nanoparticles using ionic gelation method. J. Chem. Pharm. Sci. 2013, 6, 106-112.

45. Manikkam, R.; Pitchai, D. Catechin loaded chitosan nanoparticles as a novel drug delivery system for cancer-synthesis and in vitro and in vivo characterization. World J. Pharm. Pharm. Sci. 2013, 3, 1553-1577.

46. Kasoju, N.; Bora, U. Fabrication and characterization of curcumin-releasing silk fibroin scaffold. J. Biomed. Mater. Res. B 2012, 100B, 1854-1866. [CrossRef] [PubMed]

47. Erasto, P. Antimycobacterial sterols from aromatic stem sap of Commiphora eminii. Engl. J. Adv. Sci. Res. 2012, 3, 27-31.

48. Khan, T.A. Reporting degree of deacetylation values of chitosan: The influence of analytical methods. J. Pharm. Sci. 2002, 5, 205-212.

49. Shadrack, D.M.; Mubofu, E.B.; Nyandoro, S.S. Synthesis of polyamidoamine dendrimer for encapsulating tetramethylscutellarein for potential bioactivity enhancement. Int. J. Mol. Sci. 2015, 16, 26363-26377. [CrossRef] [PubMed]

(c) 2016 by the authors; licensee MDPI, Basel, Switzerland. This article is an open access article distributed under the terms and conditions of the Creative Commons Attribution (CC-BY) license (http://creativecommons.org/licenses/by/4.0/). 